\title{
To know how to find. To find without knowing: Wisdom in the Gospel of Thomas ${ }^{1}$
}

\author{
J Liebenberg \\ Research Institute for Theology and Religion \\ University of South Africa
}

\begin{abstract}
At the SBL meeting in Orlando in 1998, the contemporary metaphor theory practised by cognitive linguists such as Lakoff, Johnson and Turner, was used to identify some of the basic metaphors appearing in Thomas 1-5, which the author believes to be important for coming to terms with the metaphoricity of many of the sayings in the Gospel. The ensuing discussion of Thomas 08 and Thomas 109 is yet another attempt to show how the insights of cognitive linguistics, which have for the most part been ignored by contemporary commentators on the parables and aphorisms of Jesus, can perhaps provide us with fresh insights into this part of the sayings of the Jesus tradition.
\end{abstract}

\section{INTRODUCTION}

In order for me to properly address the issue set out in my title I have to first set out some of my presuppositions regarding metaphors and the metaphoricity of poetic language expressions such as the parables and aphorisms of Jesus. Unfortunately space allows only a few very brief statements in this regard ${ }^{2}$.

\footnotetext{
1 This paper was presented at the Thomas Traditions Group of the SBL in November 1999. It is based on the author's 1997 doctoral dissertation, "The language of the Kingdom and Jesus: Parable, aphorism and metaphor in the sayings material common to the Synoptic tradition and the Gospel of Thomas, Humboldt Universität, Berlin with Prof Dr C Breytenbach supervisor.

2 For a more comprehensive treatment of the subject, see Liebenberg, The language of the Kingdom and Jesus (2001:1-167).
} 
According to the contemporary theory of metaphor as developed in cognitive linguistics during the past two decades, metaphor is not a matter of language but of thought. Metaphoric utterances are metaphoric because they induce a mapping of one concept onto another. Metaphor does not only belong to poetic language, but forms an integral part of ordinary language use. Poetic expressions such as the parables do not create their novel metaphors in isolation from ordinary language use, but utilise the same conceptual instruments which characterise ordinary everyday metaphoric expressions. Among these, basic or conventional metaphors such as understanding life as a journey, form an integral part. Basic metaphors form an integral part of the conceptual world of any community - without them it would be extremely difficult to create novel ways of speaking about the world and experience. If a community has a strong selfidentity it follows that they would have their own basic metaphors, apart from those shared with the outside world.

In a study on the Kingdom parables and aphorisms in the gospel of Thomas (Liebenberg 2001:137ff), it became evident that the first few sayings of the gospel presuppose a number of such basic metaphors. These include being/state is knowledge; revelation is disclosure of the hidden; wisdom is treasure; wisdom is hidden; revelation as insight into the mundane. These will also form the backbone for my interpretation of the Gth 109, Gth 08.

For a language expression to induce a successful metaphor, the two concepts that are juxtaposed with one another should share a generic-level structure. The more "self-evident" such a common generic-level structure is, the easier it is to make sense of a metaphor. For instance - it is much more difficult to make sense of an expression such as life is a chair, than it is to understand the metaphor life is a journey. This is because both life and journey are processes with definite beginnings and ends, with stages, et cetera.

The understanding of metaphor as a conceptual mapping from a source to a target domain, in which a common generic-level structure enables the detail and extent of the mapping is especially relevant for our understanding of the parables since these utilise the plot of the parable stories as generic-level 
structure to effect their detailed metaphoric mappings of - for instance - the Kingdom.

\section{THE RECEPTION OF THE PARABLE OF THE FISHNET IN GTH 8}

\subsection{The narrative elements of the parable of the fishnet in GTh 8}

Framing: And he said:

Introduction: "The human one ${ }^{3}$ is like a wise ${ }^{4}$ fisherman (ayoycu2€ $\overline{\mathrm{PP}} \overline{\mathrm{N}} \mathbf{2} \mathrm{HT}$ ) who cast his net into the sea.

Gathering: (and) drew it up from the sea full of little fish.

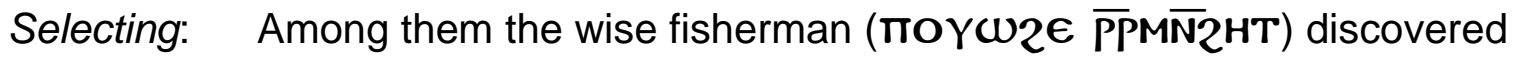
a large fine fish.

Discarding: He threw all the little fish back into the sea

Choosing: he chose the large fish without difficulty/effort (XCUPIC 2ICE).

Application: Whoever has ears to hear, should listen."

\subsubsection{Introduction}

The strange introduction which does not indicate GTh 8 as a Kingdom parable does not influence the manner in which the metaphoric mapping takes place. The only difference with the so-called Kingdom parables is that the target field is specified differently. ${ }^{5}$

\footnotetext{
3 Jeremias (1963:85) conjectures quite unnecessarily that because of the fact that in the preceding saying the word "human" occurs four times, "daß... unter Einfluß ein koptischer Schreiber an Stelle des richtigen mïntero (=Königreich, basile...a) fälschlicherweise nochmals ein rôme (=Mensch) schrieb".

4 It is also possible to translate here "sensible" fisherman, as a way of perhaps "softening" the contrast between the description of the person and the actions/events in which he is involved. However, as would become clear in the discussion below, it is precisely this contrast between the wisdom of the person and the ordinariness of his actions which forms an essential element in the understanding of the parable. Most scholars do translate "wise" here.

${ }^{5}$ Some commentators read an element of individualisation behind the introduction to the parable. Scott (1989:314) remarks that such an individualistic reading supports both a gnostic or a wisdom understanding of the parable.
} 


\subsubsection{Gathering}

The wise fisherman pulls up the net ${ }^{6}$, full ... of little fish. The parable teases the listener a little, because at the first mention of the net as being full, it appears to confirm the wisdom of the fisherman. But his wisdom does not enable him to catch only large fish and so the mention of the fullness of the net appears to be rather ironic. A wise fisherman with a net full of little fish is worse off than an ordinary fisherman with a small catch of normal-sized fish.

\subsubsection{Selecting:}

Immediately after mentioning that the net was full of little fish, the parable again refers to the wisdom of the fisherman, this time in a phrase which apparently links discovery with wisdom: $\overline{\mathrm{N}} 2$ Paï $\overline{\mathrm{N}} 2 \mathrm{HTOY}$ aq2€ a YNO6 $\overline{\mathrm{NT}} \overline{\mathrm{BT}}$ ENaNOYG $\overline{\mathrm{N}}$ । пOYCU2€ $\overline{P P M N} 2 \mathrm{HT}$ (Among them the wise fisherman, discovered a large fine fish). The listener cannot help but immediately reflect on the relation between discovery and wisdom - is the discovery a result of his wisdom? ${ }^{7}$ Note also the

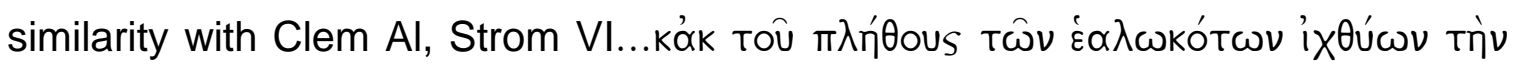

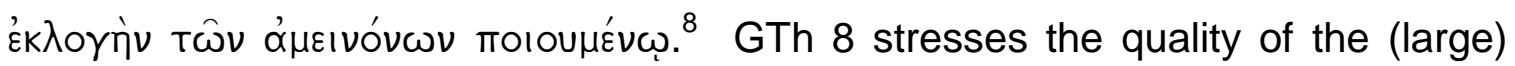
fish as does Clement, but it does seem rather odd that the parable almost seems to make the "discovery" of the large fine fish subject to the "wisdom" of the fisherman. One need not even be a fisherman at all in order to "discover" one large fish among a multitude of little ones! $!^{9}$

6 Jeremias (1963:85-86) describes it correctly as "Wurfnetz" which one throws out and gathers from the bank of the water, not the "Schleppnetz" of which Mt 13:47ff speaks which is taken out by boat.

7 It would come as no big surprise that in none of the other extant versions of the parable, i e Clem Al and also the Aesopic tradition, there is any mention of the wisdom of the fisherman, or any link between discovery and wisdom See the examples in Scott (1989:314ff). This makes GTh 8 unique.

${ }^{8}$ Clem Alex, Strom VI, (95) 3.

9 If one accepts that this is the connection that the parable wants to make one has to accept that either the scribe of this parable was not very intelligent, or that he did not think much of the intelligence of his listeners. 


\subsubsection{Discarding and choosing}

That the man had to throw the little fish back, suggests that they were at least big enough to be caught. ${ }^{10}$ In fact the phrase: acNoYXE NNKOYEI THPOY

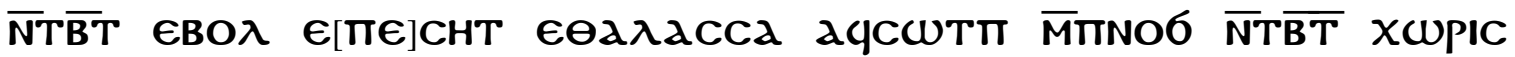
2ICE, (he threw back all the little fish into the sea, and without any effort/ worrying, chose the large fish) is strange on two accounts. The first being the fact that he, as a wise fisherman threw back the little fish, and the second, that it is stated he did so without difficulty (XCUPIC 2ICE). How should one understand this last sentence? Logically it is impossible to see how it could be difficult ${ }^{11}$ to throw back the little fish and choose the large fish. It would appear to be ridiculous of the parable to expect people to believe the wisdom of the fisherman enabled him to choose the large fish - that is a distinction every fisherman (every "fool" even!!) can make - (or can he?). Again the attentive listener is prompted into further reflection on the significance of the fisherman's "wisdom". However, before we continue, another remark is in order.

The two sentences (GTh 8:2, 3) should not be seen as describing consecutive actions. ${ }^{12}$ Since the parable has already made it clear that the man had discovered the fine large fish in GTh 8:2, it is unlikely that GTh 8:3 should be viewed as describing a consecutive action. GTh 8:3ff is not grammatically dependent on the previous sentence and it also does not follow quite logically as a sentence describing the resultant action to the remark "(he) found a large, fine fish". It appears rather that it is a description of the normal practice of the selection of fish: One would throw out, one by one all the small and/or useless

\footnotetext{
10 The Aesopic version of the story specifically mentions that the little fish escaped through the mesh, but that the big ones remained. But apparently we have an instance here where the fish were just big enough to be caught by the net, but still not of any use to the fisherman. That is why the parable is at pains to point out their size twice.

11 Note that the act of choosing "without difficulty" (XCUPIC 2ICE) is made in a context where the fisherman has been qualified by the descriptor "wise" (PMN2HT) twice, so that it is impossible for the listener not to be puzzled by the expression.

12 So also Jeremias (1963:86, n 151) "Hinter ïntbt ïkûj ist ein Einschnitt zu setzen, mit ïnchraj ïnhêtû beginnt ein neuer Satz."
} 
fish, and pick/choose the useful and/or large ones. ${ }^{13}$ The fact that the parable

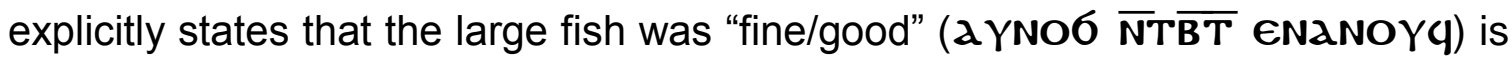
perhaps an indication that the little fish were not discarded because of their size only, but because they were unfit for use by the fisherman for some other reason - perhaps they were not edible. ${ }^{14}$ Whichever the case may be, no fisherman throws a net full of fish away for no reason. ${ }^{15}$

\subsubsection{Application}

In the light of the individualistic tone of the parable, the exhortation to listen enhances the importance of its message for everyone "who has ears". It should be seen as a reminder that the parable meaning is not as obvious as it seems. Such a dramatic warning after such a seemingly "silly" parable should surely warn especially the modern interpreter not to be mislead by the apparent foolishness of the story which ascribes "wisdom" to a fisherman who is able to choose a fine large fish "effortlessly" in favour of a bunch of little ones.

\subsection{The parable of the fishnet in GTh 8 as metaphor}

Understanding the metaphoric nature of this parable is difficult on two accounts. The first, and most important is without a doubt the fact that the story itself does not appear to make much sense. While it appears that the crux of the parable story is somehow related to the wisdom of the fisherman, it is nevertheless very difficult to understand precisely how his wisdom is related to the actions and events of the story.

The second problem with the metaphoric reading of the parable lies in the fact that the mapping between wise fisherman and human is not so far removed

\footnotetext{
${ }^{13}$ This is the same practice which is presupposed by the parable of the fishnet in Mt 13:47-48.

14 Bauer's (1962:284) suggestion that the parable was created under influence of that of the pearl, and that it anticipates "die christliche Fischsymbolik" reflects his failure to understand the narrative on its own terms. Lindemann (1980:217-218) correctly points out the differences between GTh 8 and Mt 13:45-46.

15 Again, our knowledge of what the selection of fish entails allows us to gather that the fisherman did not just throw the little fish back into the sea at will. GTh 8:3, which presupposes knowledge of how fishermen actually sorted their catch prompts us to make this conclusion.
} 
conceptually as is the case when one has to do with the Kingdom being mapped by fishing activities. The lack of conceptual distance between "the human one" and "a wise fisherman" implies that the actual conceptual mapping is determined by the qualification "wise". ${ }^{16}$ This means that unless one is able to determine how the parable depicts the "wise" fisherman" in comparison to ordinary fishermen it would be impossible to designate its metaphoric understanding of "the human one". Consequently, the metaphoric interpretation of the parable is completely dependent on the success one has in coming to terms with the seemingly ridiculous remarks about the wise fisherman in the story section of the parable first: This returns us of course to the parable story:

After it initially seemed to be confirmed by the mentioning of the full net, the expectation created by calling the fisherman wise is invalidated since his net is full of little fish only. Apart from the obvious irony in this section of the story, one should realise that this really represents a crisis for the fisherman, since it means that his whole attempt was to no avail. ${ }^{18}$ Being a wise person, it appears, does not enable the fisherman to have more success in fishing than any other fisherman. Second, in the description of the "finding/discovery" of the large fine fish, the parable is again taking for granted that the listener would know the only way this was possible was if the fisherman acted like any other fisherman after a normal catch, namely that he started sorting them out as was normal practice -

\footnotetext{
16 If one argues that "human one" as a concept includes different groups of human beings, including fishermen, then the "degree" or "extent" of the mapping is much less than when one compares a human being with a dog. It is the "closeness" or the lack of semantic distance between human one and fisherman (as opposed to kingdom and fisherman, for example) which prompts one to look very carefully at the significance of the fact that the fisherman is described as "wise".

17 Actually a fisherman who was "a wise one/person" cf Westendorf, p 164. So also Scott (1989:315) who calls this "an explicit marker".

${ }^{18}$ A net full of little fish is as good as no fish at all! That this is indeed to be understood here, is clear from the explicit mention that is made of the one fish which is not only large, but also

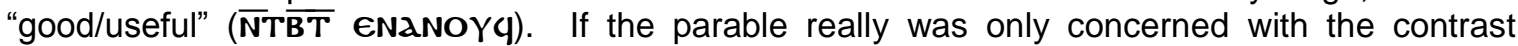
between "little" and "large" the quality (usefulness) of the large fish would not have been stressed. This implies that the other fish were not only small, but also useless. And if this was indeed the case, it did represent a crisis because it meant (at first sight at least for the fisherman, and also for the listener who still does not know that there would at least be one large fine fish), that the fisherman had to reckon his work was fruitless. In this respect, the image evoked by the parable for the listener should not be underestimated.
} 
by throwing the small ones back into the sea. So also in discovering the large, fine fish which is part of the catch, the wise fisherman is not any different than any of the other fishermen. Thirdly, describing the fisherman as choosing the large fish, without any difficulty, does not elevate him above any of his contemporaries. $^{19}$

The parable becomes a parody according to which the wise fisherman is actually no different in any respect from his fishing companions at all - except for his (useless) wisdom of course! After first creating the impression that a metaphoric reading of the parable would be dependent on the wisdom of the fisherman distinguishing him from his fellow fishermen, the story then systematically and deliberately demonstrates just the opposite. The reader of the parable story has one of three choices: S/he can regard the story teller as obtuse, and/or regard the parable as a very inept attempt to modify an existing parable (or perhaps proverbial story), or s/he can take the tension, the incongruity which runs throughout the story seriously and ask for its significance. It appears that options one and two should only be considered once the last proves to be futile. So the listener is forced to ponder the meaning of the parable yet again, and in this second reflection, to realise that what the parable is questioning, is a specific understanding of wisdom itself!! By deliberately calling the fisherman wise, while at the same time showing pertinently that his fate and actions are nothing different from what would be expected of a normal fisherman, the parable is juxtaposing a specific view of wisdom with events and actions which are incompatible with precisely such a view of wisdom. It is a parody of a view of wisdom as something extraordinary, something leading to extraordinary behaviour and which causes someone (like a fisherman for example) to relate differently towards his environment than other fishermen. The wisdom of Gth 8 is that of someone who knows how to find.

\footnotetext{
${ }^{19}$ Certainly, making this choice in the process of sorting out fish is fairly simple, yet the parable story ends by depicting and ordinary act from the image-schema of fishing (sorting) as if it is extraordinary. But the reader/listener familiar with the practice of sorting fish would not be fooled by this conclusion, and would immediately question its appropriateness. To describe the "choice" of the fisherman as something special is certainly absurd.
} 
The use of irony ${ }^{20}$ throughout the parable story then serves to drive the point home that the wisdom the parable wants to exemplify is not to be confused with a pursuit of wisdom which leads to a radical break with the "real world". This is why the wise fisherman is portrayed in such ordinary terms. But what is the wisdom which the parable wants to promote like then? It would appear that a more precise reading of the parable requires additional background, and in this respect it was mentioned before that the gospel presupposes the conventional conceptual metaphor revelation is knowledge of the mundane which is reflected by sayings such as GTh 3:3ff, 5,80 et cetera. Once one realises its relevance for GTh 8, it is apparent that the gospel's idea that finding revelation is not linked to some "otherworldly" or "transcendent" revelation, but is closely linked with the mundane (what is before one's eyes). It is this idea which dominates an understanding of this parable. The parable links up and confirms the idea which we find elsewhere in Thomas that the wisdom for which one has to strive is not an esoteric wisdom - as is so often presupposed (suggests the parable writer). It is rather a wisdom which enables one to find revelation in the ordinary, in a similar fashion that the wise fisherman found the one large, fine fish among the many little ones, as he went about his normal practice of sorting out the fish, even though at face value it must have seemed as if there was nothing to find. Just as he was not intimidated or discouraged by the first view of this multitude of little fish, but started sorting them out, so also the wise human being would not be discouraged when confronted with the apparent worthlessness of that with which s/he is confronted with everyday, but will continue to "sort the fish" knowing, that (recalling the proverbs "he who seeks will find" ${ }^{21}$ and perhaps the proverb "Among the great number of small pearls there is the one, and in the great catch of fish there is the fine fish"22) eventually $\mathrm{s} /$ he will find/discover revelation, in

\footnotetext{
20 Again, I refer to Kittay's (1987:291) distinction between metaphor and irony, according to which irony does not cross conceptual boundaries. When the parable story wants to show that what people normally understand (in the mind of the parable at least) to be wisdom, is not wisdom at all, but suggests another view on wisdom, by ridiculing this first view, we therefore have to do with irony and not with metaphor. Incidentally, I think this "tension" in the story section of the parable would fit Harnisch's (mistaken) understanding of what constitutes parabolic metaphor.

${ }^{21}$ GTh 94, Jesus said: "One who seeks will find, and to one who knocks it will be opened".

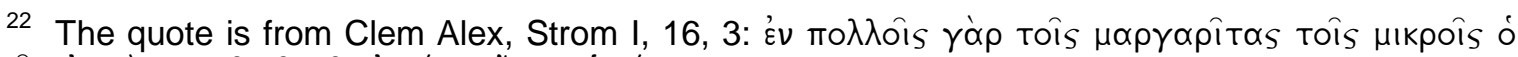

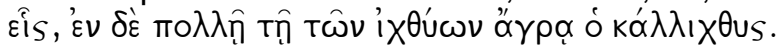


exactly this seemingly trivial, worthless normality. Similarly, in the parable story, the focus is not so much on the contrast: little - large, as on the contrast uselessvaluable. $^{23}$ The little fish were thrown away because they were worthless to the fisherman, but he kept the one large, fine fish because it was valuable to him as a fisherman. ${ }^{24}$

The parable performance demonstrates in a very provocative way that the wisdom which characterises the wise human being is not something exotic, but in fact just the opposite, it is not something which removes one from the mundane, which enables or urges one to escape the mundane, but a quality which enables one to find "revelation" in the mundane. The wisdom of GTh 8 is no esoteric wisdom. ${ }^{25}$

The pragmatic function of this parable in the context of the Gospel of Thomas can hardly be underestimated. The gospel continually stresses wisdom and finding, so that these two words in the parable would not have gone unnoticed. It is also true that the gospel treads a fine line between dis-

${ }^{23}$ Completely arbitrary is Lindemann's (1980:218) contention that "Im Bild vom großen und guten Fisch zeigt sich die Größe und Einzigheit der Gnosis" because (1) it completely misreads the irony in the parable story and (2) it has no grounds with which to motivate such an equation of "large, useful fish" with Gnosis.

24 In making the metaphoric mapping one should be careful not to make the "largeness" in itself the point of the parable, because in the parable story the fish is also described as "fine". In the context of the source field, that of fishing, finding the large, fine fish meant the difference between success and complete failure. This then is also the aspect which is mapped by the parable as metaphor, and not the focus on the largeness, as for example Schrage (1964:40ff) and Scott $(1989: 315)$ does. Because they do not first attempt to understand what the significance of the find of the large fish within the story of the parable itself is, they mistakenly make the size of the fish the metaphoric focus of the parable. One should realise that what the parable intends to map is the unique relation of the source field established between the wise fisherman and his environment, his circumstances. To paraphrase Lakoff \& Turner: "The metaphoric mapping keeps the generic-level structure of the target field intact, except for that element which it specifically wishes to change" and which is in return, dependent on the changes suggested by the source field $(\mathrm{J} L)$.

25 Note that in this reading I take for granted that the parable had the conceptual metaphor revelation is discovery/knowledge of the mundane in mind, in an attempt to understand what the parable might have meant for the model listener of the Gospel. However, even if one does not agree that this conceptual metaphor was evoked by the use of "seek, find \& wise" in the same context, it still does not invalidate a reading according to which the parable puts forward a view that the truly wise person is the one who finds something worthwhile in the everydayness of life. Irrespective of how one contextualises the parable, its metaphoric mapping makes it clear that it is advocating a specific understanding of wisdom by ridiculing another - using the story of the wise fisherman as source field in its mapping. 
engagement from the world ${ }^{26}$ and a specific finding of revelation in the mundane, although I feel that the last is perhaps emphasised a little more. ${ }^{27}$ Seen from this perspective, the parable of GTh 8 also serves to explain that the wise person is not the one who disengages from the world, but rather who finds that which is of value precisely within the mundane. In that sense the parable serves as an exhortation to the listener to forsake the pursuit of that wisdom which it ridicules, and to strive for the wisdom which is in line with one of the most important conceptual metaphors in the book revelation/discovery is knowledge of the mundane, since this can only happen if one is engaged with the world, with the mundane. Understood in this way, it becomes clear that there is no typical "gnostic" understanding of wisdom at work in this parable, on the contrary, it appears to be advocating an understanding of wisdom which is the opposite of a Gnostic, esoteric understanding of wisdom. ${ }^{28}$

\section{THE RECEPTION OF THE PARABLE OF TREASURE IN GTH 109}

The narrative elements of the parable of the treasure in GTh 109:

Framing: Jesus says:

Introduction: "The Kingdom is like a person, who had a treasure hidden in his field

First owner: (But) he did not know ( $\overline{\mathrm{Na}}$ TCOOYN EPOq),

-at death (he died),

-he left it (a $q K a \lambda q)$ to his son.

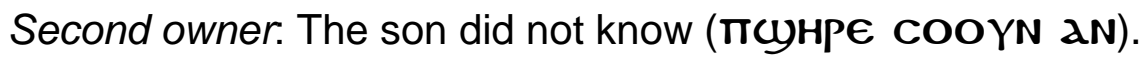

-he took over the field

-he sold it (actaac).

26 The following sayings seem to support abstinence from the world or at least realising recognising the world for what it really is: $21: 6 ; 27,110$. See the discussion of GTh 110 in chapter 2 .

${ }^{27}$ GTh 3, 5, 6, 14, 24, 56, 77, 80, 113.

${ }^{28}$ Of course this engagement with the world should be seen within a very specific perspective, that of seeking and finding the kingdom and/or revelation (GTh 5) and not as conformity to the world. 
Third owner: The buyer (did not know? $)^{29}$

-he went ploughing.

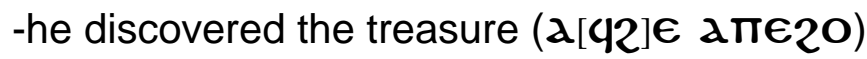

Conclusion: He began to lend money at interest to whomever he wished."

- $\quad$ First owner: The parable is set up by the lack of knowledge of the initial owner, the treasure was hidden and not known to him ( $\overline{\mathrm{Na}}$ TCOOYN €PO৭). After the introduction of the parable, the first information provided about the initial owner is his ignorance. The result of the ignorance is obvious, the man eventually died and left the treasure (аскада) (not the field) to his son, without ever discovering it. The reference here is meant to be ironic since there definitely was no intent to leave the treasure as inheritance to his son when he died.

- $\quad$ Second owner: The first remark provided about the son is that he did not

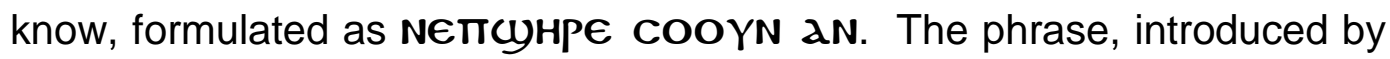
the praeteritum, provides the background against which the son sold the field. It is important since it not only provides information about the son's actions but, perhaps even more important it serves to create a certain expectation with the listener. As the second reference in as many sentences to lack of knowledge it induces the listener to expect that the solution to the complication of the parable will in some way be related to knowledge about the treasure, an expectation that proves to be totally misguided, and which in the end facilitates the turning point of the parable quite successfully as will become clear below. But first, a closer look at the second owner and his actions.

Note again the use of irony in the description of the sequence of events. The father gives (unintentionally) the treasure to the son, the son

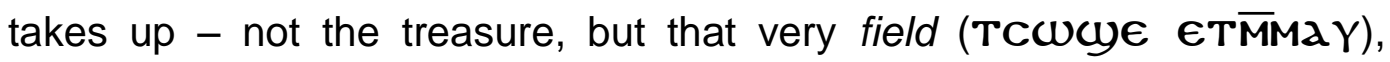
containing the treasure of which he is completely ignorant, and he sells it

\footnotetext{
29 The carefully structured elements of the parable suggest that the continuation of the idea of ignorance be supposed here as well. The fact that it is not specifically mentioned rather confirms this than the other way around. See the discussion below.
} 
(ie, the field, аqтаגс). The formulation confirms his ignorance - being given a treasure (albeit unintentionally) he takes over a field. He sells the field because it is worthless to him with the implication that he intends to get value from it, another ironic twist in the parable. Even the wordplay serves to underline this almost overbearing irony of the parable: Imagine someone listening to the parable and hearing the assonance between ачкаaq \& астаac, the first underlining that son inherited a treasure, the last in contrast that he sold the field with the implied intention of profiting from his inheritance!

- $\quad$ Third owner: According to convention the listener will expect the solution of the parable to come with the third element of the parable. In accordance with the "clues" provided by the performance of the parable up to this point the listener also expects the solution of the parable to be in some way related to knowledge about the treasure. But no mention of either knowledge (or ignorance for that matter) follows! The created expectation is shattered. The listener expects a reference to knowledge, instead the parable is silent.

The person who bought the field went ploughing and discovers the treasure. Again the formulation of the phrase is important: açє €qсKa€l aq2€ aाாє20. The discovery of the treasure is a direct result of his ploughing of the field, the circumstantial $€ q$ cka $€ \mathbf{l}$ describing the condition under which he made the discovery. ${ }^{30}$ Here lies the crux of the parable - both the father and the son would have discovered the treasure if only they had ploughed the field! One could not blame them for their ignorance, but one could blame them for not working the field. Again we have the irony - the son sells the field in order to profit from his inheritance, the buyer wants the field to plough (work) it, and

30 The formulation makes it clear that the discovery was not a result of the man's knowledge of the treasure. Contra Scott (1989:392) who follows Crossan in this regard. 
discovers the treasure which enables him never to work again! He starts lending money at interest to whomever he wishes. ${ }^{31}$ The verb $2 €$ occurs frequently in Thomas and indicates one of the important themes of the gospel, ${ }^{32}$ although the verb is not used exclusively in a figurative context. ${ }^{33}$ It is possible to argue that it should be understood primarily in a literal sense. However, as I would argue in the following section, it appears that a figurative understanding of the verb is to be preferred, similar to the "finding" of which GTh 1 and other sayings speak, with the difference that here no specific mention is made of seeking which results in finding.

\subsection{The parable of the treasure in GTh $\mathbf{1 0 9}$ as metaphor}

The saying raises the following questions:

- What is meant by treasure - does it refer to material wealth, or is it a figurative way of speaking about "wisdom"? What does it mean to "discover the treasure"?

- What is the significance of the treasure being "hidden"?

- Why is lack of knowledge so important throughout the parable?

- What is the significance of the phrase "began to lend money to whomever he wished" especially in the light of GTh 95? What light does GTh 108 and 110 provide for its interpretation?

\footnotetext{
31 It has been noted, cf Davies (1983:10) \& Scott (1989:391) that this ending to the parable is in contrast to other sections of the gospel where merchants and businessmen are denounced (64, 76). In fact GTh 95 prohibits the lending of money at interest. Despite this fact, and also that it possibly is secondary to the parable proper, it only serves to enhance what was inherent in the parable anyway, ie that the man found more than what he needed. The focus of the parable is directed towards the eventual finding of the treasure. It is the implied consequence of this finding which is taken up and developed further by this phrase.

32 Cf GTh $1 ; 8 ; 38 ; 49 ; 56 ; 58 ; 76 ; 77 ; 80 ; 110$. In these instances there appears to be an element of GTh 1 implied on an inter (intra?) -textual level in the usage of the term.

${ }^{33}$ Cf GTh $21 ; 64 ; 68$. The use of the verb here does not appear to have any intertextual links to its prevalent uses in the Gospel.
} 
I start with the first question, what is meant by treasure $\left(\boldsymbol{\epsilon}^{\mathbf{2 0}}\right)$ here? It is possible to argue that that "treasure" should be understood literally here so that it follows that the discovery of treasure here must be judged negatively. This would be supported by sayings such as GTh 63-64 and Thomas' aversion for the world. But there are other sayings in the Gospel which also use similar imagery, but then in a different sense, sayings such as GTh 3 (lack of self-knowledge is poverty); 29 (the spirit is wealth); 41 (possession is good); 76 (the Kingdom is a treasure) and 81 (let one who has become wealthy, reign). This implies that one at least has to consider a metaphoric understanding of "treasure" in this parable as well. It is simply not sufficient to say that for "Thomas wealth is bad", and consequently to see every use of the word treasure, wealth (or others from the same semantic field) as a negative statement. GTh 3 goes so far as to state that someone who does not have self-knowledge "is poverty". It is of course much easier to say that "poverty" should not be understood literally in GTh 3, but for GTh 109 it is perhaps not quite so apparent.

What then, are the (possible) conventional metaphors one can identify in the Gospel that have something to do with treasure? The conventional metaphor wisdom/knowledge is treasure which, apart from being central in the wisdom tradition also underlies GTh 3 is known to most of us with any knowledge of wisdom tradition. Understanding this parable's reference to "treasure" at least implies that one should consider whether it is at work here especially when one considers the reference to ignorance throughout the parable. The combination of the phrases about the hiddenness of the treasure, and the lack of knowledge about it potentially allows recollection of the following conventional metaphors: knowledge/wisdom/understanding is something hidden (cf GTh 1, Pv 2:1-4); being/state is knowledge; (GTh 3). ${ }^{34}$ This makes a metaphoric understanding of the parable quite likely.

\section{EXCURSUS}

Most persons familiar with Thomas might be tempted to read the parable in GTh 109 metaphorically, were it not for the phrase which concludes the parable: "...

${ }^{34}$ For these basic metaphors in GTh 3, see the discussion of GTh 56, 80 and 110 in Liebenberg (2001) chapter 2. 
and began to lend money at interest to whomever he wished" since GTh 95 expressly prohibits lending money at interest. The conclusion of the parable, ending in a description of an event which is so clearly against the command of GTh 95, then appears to encourage a different interpretation altogether. It should be noted that such a reading of the parable implies that none of the references in the parable be taken metaphorically, and that the parable is seen as an example story in order to exemplify behaviour which is to be totally condemned. Usually such an understanding sees GTh 110 as confirmation that the parable is talking about material wealth. As I have tried to show above, this reading of GTh 110 as referring to material wealth is probably not correct. Furthermore, it also appears to me that one should be very hesitant to interpret the sayings in Thomas in terms of their immediate context, since their introductions "Jesus says" seem rather to argue against such a practice. ${ }^{35}$ But if one does want to argue from context, the possible influence of GTh 108 cannot be ignored. It would appear that this saying also provides ample material which could serve as context against which to interpret GTh 109 if one wished to do so. ${ }^{36}$

However, the basic problem with the view of the parable as referring to material wealth is a failure to regard the phrase "and began to lend money at interest to whomever he wished" as metaphoric, because it is in direct contradiction to GTh 95. But just because "lending money at interest" is negatively judged in GTh 95 does not mean that a phrase containing the same words cannot be used as part of an utterance of higher complexity in order to map conceptually onto something else in a positive sense. If the treasure the man finds is supposed to map onto "wisdom", i e if he is depicted as finding wisdom/understanding, then it follows that the phrase "and began to lend money

${ }^{35}$ See Liebenberg (2001) chapter 5, where I make some comments in this regard.

36 GTh 108:2-3 similarly talks about the discovery of hidden things, actually about their "revelation", recalling the conventional metaphors revelation is unveiling what is hidden; discovery/revelation is knowledge of the mundane. The mention of "the hidden things" is not to be understood negatively at all, recalling instead the conventional metaphors wisdom is treasure; wisdom is hidden. Despite being unsure about the interpretation of the first part of the saying, one can be fairly certain that the expression "hidden things" does not carry a negative connotation. From the context provided by GTh 108 it can at least be gathered that "hidden things", and knowledge about them need not be seen as something which would influence one negatively. 
at interest to whomever he wished" is not meant negatively, but intended to evoke a positive metaphor to indicate the "wealth (recalling one of the conventional metaphors of wealth as wisdom)" which the man acquired, and the way it changed his life. In this respect the remarks of Lakoff \& Johnson which were quoted earlier in connection with the "highlighting and hiding" of metaphors can again be helpful. It was said that each metaphor, in order to function properly, has to highlight some features of a concept and hide others. What appears to be the case here is that, since we are not familiar with other expressions where the concept "lending at interest" are utilised to reveal something positive, we are focussing on the negative elements of the concept "interest", those pertaining to the exploitation of others, the ones also implied in GTh 95. This makes it extremely difficult for us to imagine that the phrase could be used in a metaphor which conveys something positive. But that (negative) aspect is not what the metaphor apparently had in mind, instead it wanted to focus on the person being changed to such an extent by discovering the treasure that he has much more than he needs, so much so that he can start taking the risk of "lending money at interest". In that sense one could argue that, for us as modern readers/listeners of the parable this is not a very successful metaphor because it does not succeed in hiding the negative aspects associated with the concept "interest". But that does not mean that this was also the case with the model reader/listener. It is quite probable that for her there was no problem in understanding the statement as describing the new status of the person, how finding the treasure changed his state of existence.

If this were the only case of this happening in our sources, such a position would perhaps have been more difficult to defend. However, consider the following two examples from Matthew where o"фis is used in both a positive and

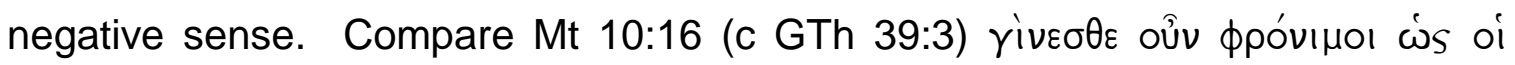

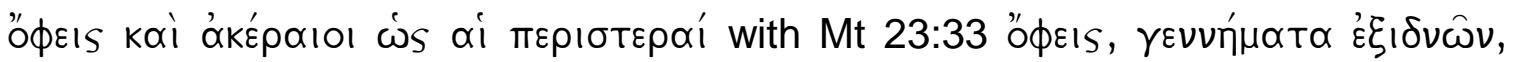

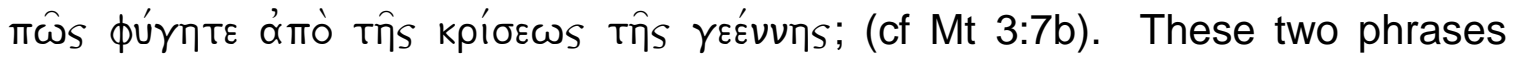
utilise the same concept to map completely contrasting aspects. A similar situation is represented by the metaphoric use of $\zeta$ úm in Mt 13:33 and 16:6. In 
both the parable (Mt 13:33) and the aphorism (16:6) the word is used to map "influence" onto another concept, in the first to the (expansion of the) Kingdom in the latter to the (negative teaching/influence of) the Pharisees and Sadducees. ${ }^{37}$ In the Matthean version of the parable (13:33) of the leaven there can be no doubt that the use of $\zeta$ ú $\mu$ is value free, and has to do with its ability to "leaven" all the dough, while the use of the same noun in Mt 16:6 is definitely meant to map negative influence. Here we thus have a clear indication that even a word

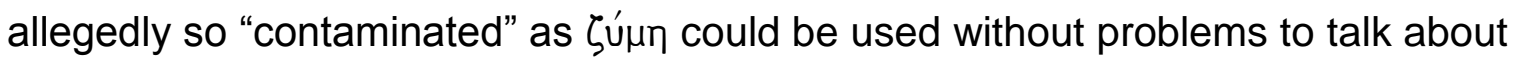
the Kingdom in a positive manner.

These examples confirm that it is not far-fetched to see a similar process at work in GTh 109. The aspect of "abundance" which forms part of the concept "moneylending-interest" is mapped here, hiding in the process the negative aspects associated with the concept. It appears that if one fixates on the negative aspects of "moneylending" when interpreting this parable, one is actually highlighting an aspect associated with it which was not the intention of the parable at all. The fact is that there is no indication from the text of the

37 Scott (1989:321-329) has argued that it is the modern understanding of leaven to be identical with "yeast" which has blinded commentators to the fact that leaven was usually used in metaphors indicating negative influence, and that consequently we should also understand the use of zÚmh in the parable in terms of this "negative valuation". His argument runs that since all the instances where it is used indicate negative influence this must also hold true for Mt 13:33. Since scholars usually see the Kingdom as holy and good, it was only natural that this aspect of the metaphor would be ignored, indeed changed to be seen as positive. But it should be remembered that the negative aspect of the "leaven" in Mt 16:6 is a direct result of the whole construction in which it appears, and not only the word itself. After first sharing his opinion in this regard, it has become clear to me that Scott is mistaken because he does not realise that the kingdom parable represents a "novel" metaphor which was indeed so powerful and successful that it changed the way people think about "leaven" and that the process was not the other way around. The understanding of Ignatius in his letter to the Magnesians, which Scott refers to (but strangely enough ignores in his discussion), confirms also that leaven was not universally seen as negative, but that (perhaps under influence of this parable) it was also used metaphorically to just

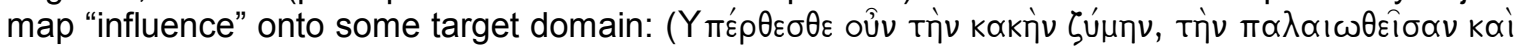

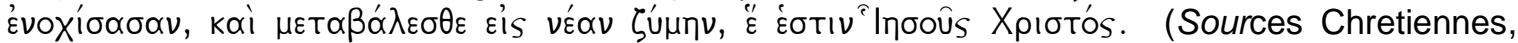
Ignace D'Antioche, Polycarpe De Smyrne, Lettres. 1958, Paris: Aux Magnesiens, X, 2, p 104) "Set aside than, the evil leaven, old and sour, and turn to the new leaven, that is, Jesus Christ." This saying confirms that the metaphoric nature of "leaven" was also determined by its "qualifiers". Scott's insistence that the use of both "woman" and "hid" confirms the "corrupting influence" of the Kingdom in discarding what was conventionally regarded as impure, loses its impact once one realises that it was only "natural" that it would be a woman who hides the leaven, (after all, turning the tables would have meant a man should have done this). Furthermore, his view that kpúmTw indicates a more negative sense than $k \alpha \lambda u n T \omega$ is simply not true. However, for a complete discussion of this issue, see Liebenberg (2001:336ff). 
parable itself that one should understand this phrase as a negative valuation of the person. Instead, the phrase "to whomever he wished" confirms this metaphorical reading, and that what the text wants to stress is the radical way in which the finding of the treasure changed the person's life. It does not sound like a value judgement at all, but like a statement confirming the person's unlimited "wealth" and the fact that it enabled him to become "richer".

To return to the parable. It would appear that the parable utilises "treasure, hidden, lack of knowledge, discovery" and the phrase "lend money at interest to whomever he wished" in such a way that it encourages one to understand the parable as a metaphor about the Kingdom and not as an example story warning of the dangers of wealth. The analysis of the structural elements of the parable already revealed that the parable wants to stress the lack of knowledge of the original owners, and the coincidental finding of the treasure by the third. Mention has also already been made of the extent to which irony ${ }^{38}$ plays a role in the parable. These aspects now all has to be combined into a coherent interpretation of the parable.

The consistent irony which is at work throughout the parable achieves two things. First it ensures that the reader knows the person who finds the treasure in the end did not have any foreknowledge of it. Secondly, perhaps more importantly, it serves to highlight what attitudes and actions (or lack of it) will eventually not lead to the discovery of the treasure of wisdom. This is achieved by its persistent ironic reference to the treasure. It is clear that neither the first owner nor the second ploughed the field at all, otherwise they would have certainly found the treasure. Furthermore, the son, selling the field in order to profit from it, epitomises what "lack of knowledge" actually leads to, that it

\footnotetext{
38 Kittay (1987:293) remarks: "Irony is a transfer of meaning within a single semantic field such that the relations between terms of that field are reversed". It is thus distinguished from metaphor in that no conceptual boundary is "crossed". When the first owner leaves the treasure to his son, it is irony because it is not his intention (since he does not know about it) to do that. He intends to leave his son something valuable, the land, but without knowing it, he gives him much more. The transfer here is between land and treasure - intending to give something (material wealth) he gives much more, the treasure (material wealth). As the parable puts it: While he is de facto giving the treasure he actually (because of ignorance) does much less (he only gives him the land).
} 
induces one to seek "wealth" elsewhere, while it is to be found in the mundane, in the ordinary, in that which at first sight does not appear to have any value at all. In this respect the parable is reminiscent of GTh 5 "Know what is before your face, and what is hidden from you will be disclosed to you. For there is nothing hidden that will not be disclosed". The third owner (being ignorant about the treasure himself) was not much different from the other two, except for the fact that he did not go and look for "treasure" elsewhere. He engages in the mundane, in the ordinary, and he finds the treasure. We are able to recognise this simple story about a man discovering a treasure to be metaphoric because we have been alerted - right at the beginning of the Gospel - to the conventional metaphors wisdom is treasure, wisdom is hidden; disclosure is knowledge of the mundane and finding/discovery is a mental process. But this reading implies that we must understand "ploughing" also in a metaphorical sense. How does this happen? By virtue of the fact that wisdom is mapped both in terms of the conventional metaphor wisdom is treasure and wisdom is hidden (which is actually a subordinate metaphor to wisdom is treasure) it is easy to understand how "ploughing" can lead to the "discovery" of wisdom. Ploughing the field therefore involves acquiring understanding, knowledge - in short, receiving revelation. Finally, one could perhaps go even further and also argue that the discovery of wisdom has existential consequences. If the references to knowledge, and the eventual "finding" of the treasure (=wisdom, knowledge) evoke the conventional metaphor state/existence is knowledge/ wisdom ${ }^{39}$ one can conclude that the discovery of wisdom results in the person acquiring a higher state of existence than before. This would tie in with the conventional metaphor revelation is disclosure of the hidden (GTh 5). The final metaphoric statement about him "lending money at interest to whomever he wished" maps in such a way that the person with discovered knowledge is able, to gain even more knowledge.

\footnotetext{
39 In other words, your state/existence is determined by the nature of the knowledge that you possess.
} 
As a parable about the kingdom, GTh 109 acknowledges that no one can escape initial ignorance about the "treasure which is hidden", evidencing similar thinking than that which underlies a saying like GTh 5 . But it insists that lack of knowledge is no excuse. The way to find the treasure, to find wisdom and therefore revelation associated with the Kingdom which entails a change of existence, is not to know beforehand where it is to be found, but the willingness to receive revelation which is the discovery of wisdom, in the correct engagement with the world, with the mundane. Although it is unclear precisely what this "engagement with the world" this "ploughing" is, it is apparent from the use of similar terminology like "treasure, find, discover" and their notion of a change of existence, that the parable has a lot in common with GTh 5, 56, 76, 80, 108, 110.

The parable evokes insight into the nature of things, into the way in which one receives revelation and also how it changes one's existence and can thus be called a pedagogical metaphor. Since becoming part of the Kingdom involves a change of existence, the parable is a metaphor on how one's existence is changed in such a way that one becomes part of it, but also how it happens that many people do not experience this change of existence. The difference between those who receive revelation, those who find, and those who do not is that the latter engage wrongly with the mundane. It is a parable on how to find without knowing.

\section{Works consulted}

Bauer, J 1962. Zum Koptischen Thomasevangelium. BZ 6, 283-288.

Davies, S L 1983. The Gospel of Thomas and Christian wisdom. New York: Seabury.

Harnisch, W 1985. Die Gleichniserzählungen Jesu. Göttingen: Vandenhoeck \& Ruprecht.

Jeremias, J 1963. Unbekannte Jesusworte. 3. neu bearbeitete Auflage. Gütersloh: Gütersloher Verlagshaus.

Kittay, E F 1987. Metaphor: Its cognitive force and linguistic structure. Oxford: Clarendon Press.

Lakoff, G 1987. Women, fire and dangerous things. Chicago: University of Chicago Press. 
Lakoff, G 1993. The contemporary theory of metaphor, in Ortony, A (ed), Metaphor and thought. 2nd edition. Cambridge: Cambridge University Press.

Lakoff G \& Johnson, M 1980. Metaphors we live by. Chicago: The University of Chicago Press.

Lakoff G \& Johnson, M 1981. Conceptual metaphor in everyday language in Johnson, M (ed), Philosophical perspectives on metaphor, 286-328. Minneapolis: University of Minnesota Press.

Lakoff G \& Turner, M 1989. More than cool reason: A field guide to poetic metaphor. Chicago: University of Chicago Press.

Lindemann, A 1980. Zur Gleichnisinterpretation im Thomas-Evangelium. ZNW 71, 214-243.

Schrage, W 1964. Das Verhältnis des Thomas-Evangeliums zur Synoptischen Tradition und zu den Koptischen Evangelienübersetzungen: Zugleich ein Beitrag zur Gnostischen Synoptikerdeutung. Berlin: Verlag Alfred Töpelmann.

Scott, B B 1989. Hear then the parable: A commentary on the parables of Jesus. Minneapolis: Fortress Press.

Turner, M 1987. Death is the mother of beauty: Mind, metaphor, criticism. Chicago: University of Chicago Press.

Turner, M 1991. Reading minds: The study of English in the age of cognitive science. Princeton: Princeton University Press.

Turner, M 1992. Design for a theory of meaning, in Overton, W \& Palermo, D (eds), The nature and ontogenesis of meaning, 91-107. Hillsdale, New Jersey: Erlbaum.

Turner, M \& Fauconnier, G 1995. Conceptual integration and formal expression. Journal of Metaphor and Symbolic Activity 10(3). (Forthcoming.)

Westendorf, W 1977. Koptisches Handwörterbuch. Heidelberg: Carl Winter. 